\title{
Increased Motivation To Learn By Using Learning Model Learning Community Students Mathematics Education
}

\author{
Sumargiyani ${ }^{\text {a,* }}$, Habibi ${ }^{\text {a }}$, Bidayatun Nafi'ah ${ }^{a}$ \\ ${ }^{a}$ Mathematics Education Study Program, Ahmad Dahlan University \\ South Ringroad Street, Bantul, Special Region of Yogyakarta 55191, Indonesia \\ *E-mail: sumargiyani04@yahoo.com
}

\begin{abstract}
This Research aims to increase the motivation of students in differential calculus learning using the Learning Community model in the class B Mathematics Education Program of Ahmad Dahlan University academic year 2018/ 2019, totaling 28 students. This type of research is a class action study consisting of planning, action, observation, and reflection phases. The instrument used in this study is an observation sheet. The results showed that the student's learning motivation increased as demonstrated by the increased motivation of learning students from Cycle 1 which was $76.5 \%$ in the high category, while in Cycle 2 increased to $81.5 \%$ in the class very High. It can be concluded that using learning Model Learning Community can improve the cultivation of teaching differential calculus of class B students UAD mathematics education
\end{abstract}

\section{Introduction}

The role of education for Indonesia is significant for a breakthrough from the Indonesian Ministry of Education and Culture to improve the quality of education. Education is the primary key to improve intellectuals and support Indonesia to be competitive in global economy through the professionalism of various parties in education [1].

Teachers are one crucial factor in the quality of education [2]. Therefore, the Indonesian Ministry of Education and Culture collected seven elements of the education ecosystem, one of which was the teacher as an encouragement [3]. The best teacher starts interestingly learning in class and encourages students to appear what is seen during the learning process to get the best learning achievement $[4,5]$. 
Learning motivation is very important to emphasize 21st-century skills $[6,7]$ and has become an essential goal in learning by other countries that excel in the field of education, namely Finland [8]. Even so, the achievement of student learning achievement in Indonesia is still not excellent, especially mathematics [4]. This is related to some problems when learning mathematics is ambiguous, easy to give up, do not like challenges, do not want to do math assignments [9]; even from year to year, most Indonesian students are not motivated, learning mathematics as a result of decreased mathematics achievement [4]. In fact, mathematics has an essential role in the 21st-century [9-11]. If motivation not taken seriously, it will cause more severe problems in the future [12]. This is a particular challenge for teachers, especially mathematics teachers [5].

Success in the process of learning mathematics when accompanied by pleasure, curiosity, and interest in learning will obtain optimal learning outcomes in the form of grades, praise, and even achievement [4]. Therefore, optimizing the achievement of student learning outcomes must be supported by the learning motivation of students themselves. This means that increased motivation does not only depend on educators, facilities, and education infrastructure but more on the active role of students who can determine the success of achieving competence [13]. Hsieh [14] concluded that learning motivation and student activity in the learning process is the key to improving teaching and learning outcomes and the quality of education.

Motivation is defined as a moving emotion [15] and a psychological process that provides purpose, direction, and intensity to shape behavior and is responsible for obtaining different results [16]. The learning motivation is a belief inherent in individuals to achieve learning goals, encourage individual behavior to make continuous efforts, strengthen the experience of cognition, and can improve learning outcomes [17]. Highly motivated students will have a high level of responsibility towards themselves, willing to take risks, have a learning plan, are dangerous, diligent, active, do not feel complacent, and always try to learn new things to get the best results [13] at the same time students can use cognitive processes or higher knowledge to learn, absorb, and maintain material that has been widely studied [18]. Thus, learning motivation can be improved through variations in learning that are applied will give a different feel from previous habits, as in [13].

Mathematics studied at every level of education, so it is not only learned from elementary schools, junior high schools, senior high schools, but to tertiary institutions and one of the majors in universities that explore mathematics is a mathematics education study program, so students need to have high motivation to learn mathematics with the nuances of education and the output of the study program is focused on becoming a mathematics teacher [19]. 
One of the courses that must be studied by students of mathematics education courses is calculus, which includes differential calculus, integral calculus, advanced calculus [19]. Differential calculus courses at tertiary institutions become prerequisites for taking other calculus courses such as integral calculus and advanced calculus, depending on the policies of each tertiary institution. The material in differential calculus includes functions, function limits, continuity, derivatives, and derivative applications. Calculus material has been studied at the high school level, and more detail is studied at the tertiary level, but differential calculus material is still considered difficult [19], tedious for students due to lack of motivation to learn as a result of laziness in students [15], and learning outcomes were not achieved by both [19].

Achievement of learning outcomes is not only influenced by student motivation but through the use of methods, models, approaches, determined by the lecturer in the learning process can also affect the success of learning achieved by students [9]. Bakar [13] states that increased motivation to learn there needs to be encouragement from educators, staff, parents, and the community through attitudes, performance of self-encouragement, enjoyable learning environment, methods, and right learning strategies so students are motivated to learn more and appreciate what he has learned. Thus, lecturers need to master learning strategies or approaches so that the subject matter delivered to students can be appropriately understood [13].

The choice of strategy or approach is adjusted to pay attention to the tendencies and needs of students in general through the mastery of learning strategies or approaches. Siswono et al. [20] states that the selection of strategies or approaches or learning models for each class is not the same based on a combination of mathematical abilities, gender, and student motivation, as in [21] states that learning motivation is related to students' ability to manage various learning models themselves in their learning activities. The use of various learning models aims to avoid the emergence of boredom in students in learning caused by monotonous conventional learning activities. Same statement by Listiadi et al. [10] that students often feel bored if every day the teacher applies the same learning model. The use of appropriate learning models so that success in the learning process will be achieved [22], by the expected learning objectives, and students will gain knowledge and abilities of the 21st-century [6]. Thus, the learning model and learning motivation are interrelated factors in supporting the quality of learning. This can be confirmed by several research results which state that by using the right learning model can increase learning motivation.

Research results show that by applying the Contextual learning, the model can increase learning motivation in calculus subjects, as in [23]. In research results [24] show that the application of the Jigsaw learning model can increase the activeness and motivation of student learning as evidenced by the students' interest and comfort when studying geometry material. In 
other research results [25] show that the application of the Student Teams Achievement Division (STAD) learning model in mathematics teaching has increased student learning outcomes, student learning independence, student activeness, student motivation, insight, experience, student creativity, and creativity.

In addition to the three learning models above, one of the other learning models that can increase learning motivation is the learning community learning model. Brophy et al. [26] states that the learning community learning model is one of the learning models that can support student motivation. The learning community learning model has a lot of traction and potential to provide real experiences for students, educators, or teachers, and staff participating in the community [27]. The learning community learning model is an organization in which its members or classmates aim to learn, collaborate with fellow members to successfully achieve learning goals, convey new ideas and seek various views and opinions in a committed manner, encourage open discussion, and implement the process of making transparent decision $[26,28]$. The understanding of the learning community learning model is a technique that can help students talk, share ideas through collaboration, learn effectively in groups, help understand how to influence others through communication with each other [29].

Learning outcomes in the learning community model are obtained from collaboration or sharing with other parties. Learning community factors were: reflective practice and teaching strategies, collaborative partnerships, changing perspectives on learning and teaching, motivation and initiative, the discipline area and lesson topics[30]. The steps in implementing Learning Community Learning [31] are as follows: 1) Formation of small groups of 2-3 heterogeneous students; 2) Presentation of material; 3) Giving tasks to each group to be discussed and worked on by group members; 4) Granting valuation; 5) Reflection and planning of the material; 6) Allow time for questions and answers.

Based on the description above, researchers are interested in applying the learning community learning model in the hope that it can increase student learning motivation and the learning model has never been applied to differential calculus courses with material limit functions and their application. Furthermore, the researcher wants to know whether the learning community learning model can increase the learning motivation of class B students in the mathematics education program UAD in the academic year 2018/2019 who take differential calculus courses?

\section{Research Methods}

The research was conducted at the Mathematics Education Study Program of the Teaching and Education Faculty of Ahmad Dahlan University, Yogyakarta. The time of implementation is in the even semester of the Academic Year 2018/2019. The subjects of this study were grade B 
students of the Mathematics Education Study Program Faculty of Teacher Training and Education, Ahmad Dahlan University Yogyakarta Academic Year 2018/2019 who took Differential Calculus courses. The object of this study is the whole learning process with learning community learning models and student motivation. This type of research is carried out by Classroom Action Research (CAR). An analysis is carried out in 2 cycles. The steps to get the data adopted from [32] shown in Figure 1.

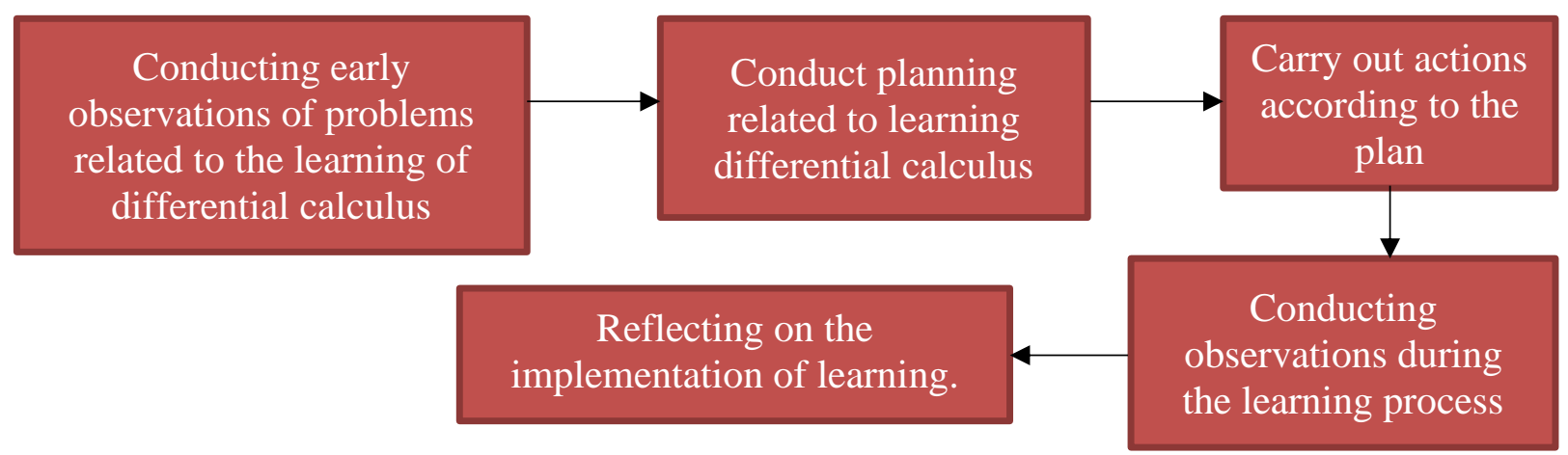

Figure 1. CAR steps

At the action stage, begin to apply learning steps adopted from the levels of the learning community learning model [31] and developed by researchers because it is adapted to the conditions in the classroom. The steps are shown in table 1.

TABLE 1. Adoption measures Model-Defay Learning Community

\section{Activities}

1. Opening

2. Lecturers form students in groups, one group of three students

3. Lecturer presents derivative lecture material

4. Lecturer gives a task to each group to be done

5. Lecturers give students time to discuss

6. Lecturers give students time to consider

7. Reflections and questions and answers to materials that have been considered

8. Planning on the material to be studied next

9. Closing

In the observing stage, observation is conducted to obtain data on student motivation while learning takes place, both in cycle I and cycle II. In the reflecting stage, reflection is done after analyzing learning motivation data, which includes data reduction, triangulation, data display, and drawing conclusions. From the results of reflection will be followed up on the next cycle if there are deficiencies or findings in the implementation of previous learning. An indicator of the success of this study is the increase in student motivation in learning Differential Calculus has achieved at least excellent criteria or range of $80 \%-100 \%$, as in [34].

According to Miles and Huberman [35] suggests that activities in qualitative data analysis are done interactively and continuously, which divides the steps into data analysis activities with 
several parts, namely Data reduction, display data, and data conclusion. As for the explanation of each of the following data analysis steps are shown in table 2.

TABLE 2. Data Analysis Steps

\begin{tabular}{|c|c|}
\hline Activities & Description \\
\hline Data reduction & $\begin{array}{l}\text { Summarizes selects the underlying things, and focuses on the essential stuff } \\
\text { and removes things that are not important. Data reduction can be made by } \\
\text { collecting data from interviews, observation results, and poll results. } \\
\text { Through reduction, the researcher will summarize, fetch the underlying and } \\
\text { essential data, categorize the data based on uppercase, lowercase, and } \\
\text { numbers. Also, researchers in the data reduction can discuss to friends or } \\
\text { other people who are considered experts to add insight to the research that } \\
\text { is to be developed. }\end{array}$ \\
\hline Triangulation & $\begin{array}{l}\text { To conduct a validation check and data held by Degan comparing and } \\
\text { utilizing data from outside or other sources. }\end{array}$ \\
\hline Display Data & $\begin{array}{l}\text { After the data is reduced, then present the data. The presentation of the data } \\
\text { can be done in the form of brief descriptions, charts, graphs, tables, Matrik, } \\
\text { flowcharts, and so on. Through the presentation of data that has been } \\
\text { compiled into the sequence so that the structure can be understood and } \\
\text { found the patterns are meaningful and allow the withdrawal of conclusions. }\end{array}$ \\
\hline $\begin{array}{l}\text { Conclusion } \\
\text { data }\end{array}$ & $\begin{array}{l}\text { The final step in qualitative data analysis is the withdrawal of conclusions } \\
\text { or verification. The preliminary findings found are still temporary and will } \\
\text { change if they are not strengthened with evidence supporting the next stage } \\
\text { of data collection. However, if preliminary conclusions are already } \\
\text { supported by valid and consistent evidence, then the end expressed is } \\
\text { credible. }\end{array}$ \\
\hline
\end{tabular}

\section{Research Results}

This study carried out as many as cycle II. The second cycle is carried out because the established success indicators have not been achieved, which is an excellent indicator. Suprapti et al. (2018) stated that if the result of the cycle I obtained the cognitive, affective, and psychomotor aspects have not reached the indicator of success, then it is necessary to do the ongoing research in cycle II with the results obtained cognitive elements, and psychomotorcritical symbols are successful, and the research has succeeded.

Cycle I planning before carrying out the research action. First, the researchers do the planning. In this cycle, I explained the definition of function limit, unilateral limit, and two-party limit, how to calculate the threshold of functions, linkage limit function with graphs planning function done based on the results of pre-research done. The activities undertaken at the planning stage are shown in Figure 2. 


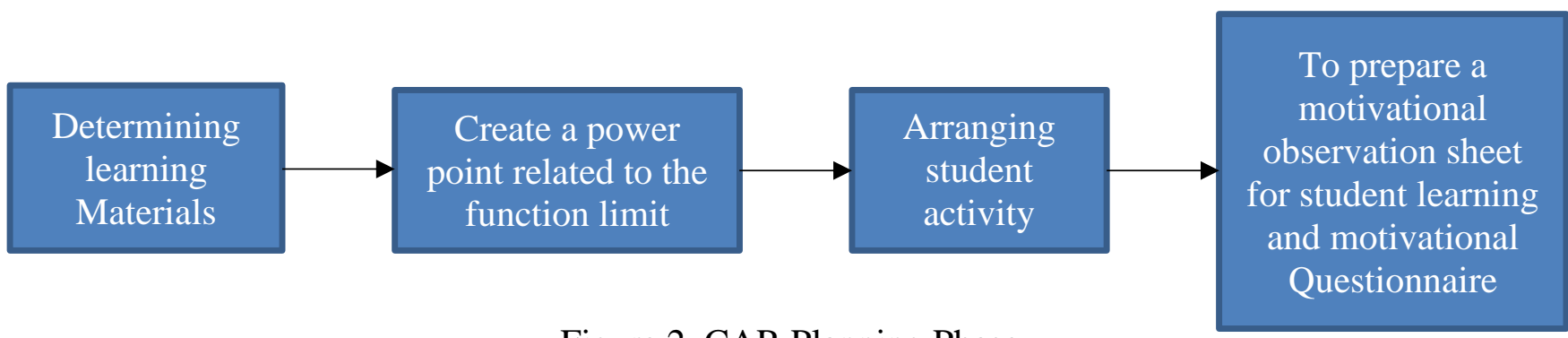

Figure 2. CAR Planning Phase

The student activity sheets are tailored to the learning objectives and are made with the material and practice of the problem. The execution action of the cycle I is implemented in one meeting $\left(3 \times 50^{\prime}\right)$. The number of students attends as many as 28 students. The learning material at this meeting discusses the limit of functions. The step-by-step activities of the learning Community lesson model in cycle I am shown in table 3.

TABLE 3. Step-by-step activity Model Learning Community on Cycle I

\begin{tabular}{ll}
\hline Activities & \multicolumn{1}{c}{ Description } \\
\hline Opening & 1. Lecturers speak and Tadarus \\
2. Lecturers ask students to focus on learning during the learning \\
process. \\
3. The lecturer conveys the exception of the function limit. \\
4. Lecturer writes about the limit of five function problems and \\
students are told to do \\
5. Lecturer motivates students to work on the issue and to remember \\
back the material limit function when in high school. \\
6. The lecturer said that "you have to be diligent and sincere in doing \\
this problem and do not give up easily if you really can not ask a \\
friend or open a book." \\
7. Of these questions, made a lecturer for the original materials convey \\
the material limit function. \\
1. Lecturers have students sit in groups, with each group consisting of \\
three students. \\
2. Lecturers told students to read LKS, books, or other references \\
related to the function limit. \\
3. Lecturer told the students to do the problem in the LKS. \\
4. Lecturers ask students to start discussing completing the training \\
problems. \\
5. Lecturer asks the group representative to write the answer on the \\
board. \\
6. Group representatives are the result of the discussion. \\
7. Lecturer gives feedback and feedback on the results of the \\
discussion \\
1. Learning is terminated at the evaluation stage. \\
2. Lecturers perform reflections by giving questions to the individual \\
tasks that must be gathered at the next meeting. \\
3. Lecturer informs that the material to be learned at the next meeting \\
is material about the form of unnecessarily
\end{tabular}


At the core stage of Step 4, the lecturer said the lecturer told students to stay focused and to solve the problem and do not easily give up. If an obstacle is asked with a fellow group member, and if there are constraints can be invited to another group. At the core activity stage in step 6, completion of the presentation is not much time-consuming, and not many have asked because the answers of each group are already the same. At the core stage of Step 7, the lecturer concluded that "the limit of a function is that the two have a limit value and have no limit (no limit). All this time you learn on the bench SLTA, the cost of a function is certainly no value. Limit functions are also differentiated two, namely unilateral limit and two-party limit, so you know the left limit and even the right limit ".

At the stage of observation carried out during action execution. Observations in this study were conducted to observe student motivation. Observations or observations of motivational learning are guided on an observation sheet that contains a statement of the motivation aspect of education.

At the stage of reflection is done by processing the motivation of learning data first, from the processed results data has been known that the motivation to study in cycle I with good criteria, so that it has not fulfilled the requirements of success indicators. Disadvantages that occur during the learning process using learning Community learning models that arise in the cycle I shown in table 4.

TABLE 4. Lack of implementation of learning Community learning Model in Cycle I

\begin{tabular}{cc}
$\begin{array}{c}\text { Disadvantages related to the learning } \\
\text { process in Cycle I }\end{array}$ & $\begin{array}{c}\text { Lack of motivation related to learning on } \\
\text { Cycle I }\end{array}$ \\
\hline
\end{tabular}

1. Some students are not accustomed to 1. Some students are less resilient in working group cooperation out the problem - the problem he thinks is difficult so that they are more likely to rely on their more clever friends.

2. Some students do not understand the 2. Some students are less able to maintain limit function material associated with their opinions because when asked and the graph of functions. ensured their answer immediately be silent because it worries the answer wrong.

3. Group discussions run longer than 3. Some students, if given a question that is planned and only some groups can somewhat difficult, less willing to work present their work. $\quad$ hard to find answers.

At the stage of reflection or improvement in order to improve student motivation is increased by increasing the persistence of students in the face of difficulties, when having a different opinion with his friend then do not immediately confused, but must Retain opinions while the opinions are believed to be accurate; And more pleased with trying to work on more varied questions. Out of some drawbacks in the, Cycle I, the improvements that are structured to improve learning in Cycle II are demonstrated in table 5. 
TABLE 5. Fixes from deficiency Cylce I

Improvements to the learning process on Developments related to the motivation for Cycle II from shortcomings in the Cycle I learning to study in period II

1. Reaffirm that every student must be active and participate in the training problems given

2. Re-explain the limit function material associated with the function graph.

3. Time for discussion is delivered to the student and all groups are required to present their work.

1. Tell students to do the problem first, before asking the answer to a friend

2. If given a question should be answered, do not worry the answer given is worth right or wrong

3. Ask students to search for answers through books or the Internet if they have difficulty working on the problem practice problems

The action of action in cycle II is performed in a single duration $\left(3 \times 50^{\prime}\right)$ - the number of students attends as many as 28 students. The learning materials at this meeting discussed the unnecessary forms. The steps of learning Community learning model activity in cycle II are demonstrated in table 6 .

TABLE 6. The step-by-step learning Model activity Community on Cycle II

\begin{tabular}{ll}
\hline Activities & \multicolumn{1}{c}{ Description } \\
\hline Opening & 1. Lecturers speak and Tadarus \\
2. Lecturers ask students to focus on learning during the learning \\
process. \\
3. Lecturers convey an exception to the function limit already studied \\
at the previous meeting \\
Core activities \\
1. The lecturer redefines the relationship limit function with the \\
function graph. \\
2. The lecturer told the students to sit in groups, with each group \\
consisting of three students. \\
3. Lecturers are given a limit function with an unnecessary type of $\frac{0}{0}$. \\
From that matter, it is expanded to discuss the other types of useless \\
shapes. \\
4. Lecturers asked students, some parts that were not yet understood. \\
5. Lecturers told students to look for references of unnecessary forms. \\
6. Lecturers give ten questions to work and as group discussion \\
material with a specific time limit. \\
7. The lecturer asked the group representative to write the answer on \\
the board. \\
8. Group representatives are the result of the discussion. \\
9. Lecturers give feedback and feedback on the results of the \\
discussion
\end{tabular}


At step 3 The core activity shows that no students are asking because they have already understood. From this activity, the student spirit worked on the task given by the lecturer. Each group does not despair in her problems or questions given. Students ' interest in doing the problem is quite high. When given the difficult question, there are some students still trying to complete or seek answers from the questions given.

At the core stage of Step 6, lecturers encourage students to stay focused and earnest in solving the problem and do not easily give up. If a student has an obstacle to inquire with a fellow group member, and if there are constraints can be asked to another group or with a lecturer.

At the core activity stage in step number 8 , the presentation time is not much time-consuming and not many are asking, because the answers of each group are already the same. At the core stage of step 9, two problems have not been resolved entirely, so that the lecturer needs to explain the answer so that all students become aware. Done discussing all of the issues that have been given, the lecturer, together with the students concluded the material that has been considered, namely there are different types of forms that have not necessarily been discussed. For the unnecessarily form that was covered, the new high school is two types, and so far they have known the not necessarily other forms.

At the stage of observation on cycle II is carried out during action execution. Observations in this study were conducted to observe student motivation. Observation of the motivation to learn the guidance on the observation sheet that contains a statement about the aspect of learning motivation.

At the stage of reflection is done by processing the motivation of learning data first, from the results of processed data has been known that the motivation to learn at cycle II with excellent criteria, so that it has reached the requirements of success indicators. During the learning process using the Learning Community learning model, which occurs in cycle II, namely: Students are very diligent in following the learning when given the training students have tried to work on their own and Not easy to give up. It is proven that students do not directly ask friends or lecturers when experiencing obstacles, hard work in working on the problem in one group looks very high. The only thing that is still in the criteria is that students are not used to defending their opinions; they are more likely to follow the answers to questions from their friends. Reflections or improvements to improve the motivation of learning students need to be done in terms of maintaining opinions and not quickly releasing things believed the outcome of the motivational observation of teaching students on Cycle I and Cycle II aimed at Table 7. 
TABLE 7. Results of Observations of Student Learning Motivation

\begin{tabular}{ccc}
\hline Indicator & Cycle I & Cycle II \\
\hline Diligently facing the task & $89,3 \%$ & $92,9 \%$ \\
Tenacious faces difficulties & $71,4 \%$ & $82,1 \%$ \\
Showing interest & $89,3 \%$ & $89,3 \%$ \\
Can defend his opinion & $60,7 \%$ & $64,3 \%$ \\
It is not easy to let go of that thing & $57,1 \%$ & $71,4 \%$ \\
believed & $92,9 \%$ & $92,9 \%$ \\
Hard work & $82,1 \%$ & $89,3 \%$ \\
Fast bored with routine tasks & $67,9 \%$ & $71,4 \%$ \\
Happy yo solve problems & $\mathbf{7 6 , 5 \%}$ & $\mathbf{8 1 , 5 \%}$ \\
Average & Good & Excellent \\
Criteria & &
\end{tabular}

From the table, it can be seen that in Cycle I there are four indicators with excellent criteria, namely: Happy to solve problems, It is not easy to let go of those things that are believed, Can maintain their opinions and be resilient in facing difficulties. In cycle II decreased for indicators that have not reached the criteria of very good, by two, namely: Happy to solve the problem, can maintain his opinion and Not easy to let go of things that are believed. From the Cycle I and Cycle II, students' learning motivation experiences. It can be seen that there is a graph shown in Figure 3 as follows:

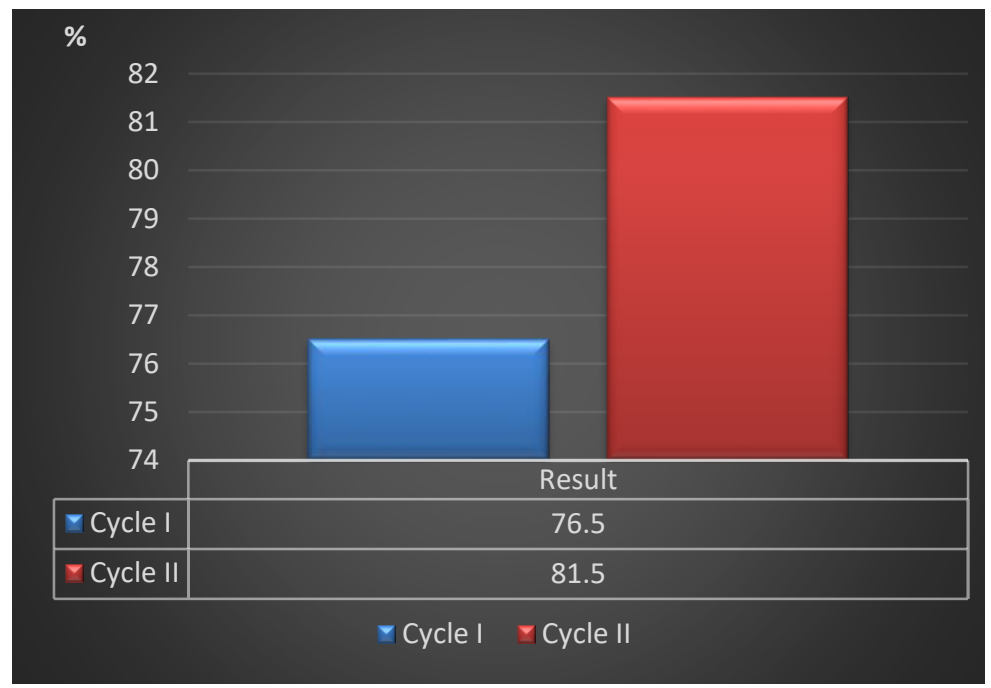

Figure 3. Students' Learning Motivation Experiences from the Cycle I and Cycle II

\section{Conclusion}

The study showed that by using the learning community, learning model can increase the learning motivation of class B students taking Differential Calculus courses in the Education Study Program of the Teaching and Education Faculty of Ahmad Dahlan University accademic year 2018/2019. Based on the results of the study, learning motivation in Cycle, I was $76.5 \%$ with high criteria, and in Cycle II, it increased to $81.5 \%$ with very high standards. So as a whole, 
it can be concluded that by applying to learn to the learning community learning model can increase student motivation.

\section{Acknowledgments}

Acknowledgments to the student of grade B Mathematics Education Program, Faculty of Teacher Training and Education, Ahmad Dahlan University, which takes the academic year differential calculus 2018/2019, and some of the parties listed in the reference in writing research results as a theoretical reference and upstream research data.

\section{References}

[1] A. Sukasni and H. Efendy, International Journal of Education. 9, 183-199 (2017).

[2] D. Sulisworo, R. Nasir and I. Maryani, International Journal of Research Studies in Education. 6, 81-90 (2016).

[3] M. o. E. a. Culture, Rencana Strategis Kementerian Pendidikan dan Kebudayaan 2015-2019 (Department Indonesian Ministry of Education and Culture, Jakarta, Indonesia, 2016).

[4] A. A. N. Fuqoha, Budiyono and D. Indriati, Pancaran Pendidikan. 7, 202-209 (2018).

[5] A.S. Posamentier and S. Krulik, The Art of Motivating Students for Mathematics Instruction (McGraw-Hill, Americas, New York, NY 10020, 2012).

[6] F. N. Afrida, A. R. RC and Y. Utanto, Journal of Primary Education. 8, 92-100 (2019).

[7] R. Rueda, in Theoretical Models and Processes of Reading (University of Southern California, 2013), p. 1241-1068.

[8] J. Hautamäki and S. Kupiainen, in Learning to Learn International perspectives from theory and practice, edited by C. S. Ruth Deakin Crick, Kai Ren (Routledge, London, 2014), p. 179.

[9] I. Kusmaryono, in International Conference on Mathematics, Science, and Education 2014 (ICMSE 2014) (Faculty of Mathematics and Natural Sciences, Semarang State University, 2014), p. 35-40.

[10] A. Listiadi, R. Sulistyowati and N. C. Sakti, in International Conference on Economics, Education, Business and Accounting (KnE Social Sciences, 2019), p. 884-902.

[11] N. Millaturrahmah, Mardiyana, and I. Pramudya, AIP Conference Proceedings. 1868, 0500024 (2017).

[12] R. M. Ryan, Journal of Personality. 63, 397-427 (1995).

[13] R. Bakar, International Journal of Asian Social Science. 4, 722-732 (2014).

[14] T.-L. Hsieh, Springer Link. 68, 417-433 (2014).

[15] M. Z. Mokhtar, R. A. Tarmizi, A. F. M. Ayub and M. D. H. Nawawi, International Journal of Asian Social Science 3, 1999-2005 (2013).

[16] J. G. Mwangi and N. L. McCaslin, Summary of Research. 16-25 (1994). 
[17] K. Shabani, Procedia - Social and Behavioral Sciences. 32, 321-328 (2012).

[18] S. Graham and S. Golan, Journal of Educational Psychology. 83, 187-194 (1991).

[19] S. Fatimah and Yerizon, International Journal Of Scientific \& Technology Research 8, 80-84 (2019).

[20] T. Y. E. Siswono, S. Hartono, A. W. Kohar, K. Karim and N. Lastiningsih, TEM Journal. 8, 677-685 (2019).

[21] B. L. L. Ng, W. C. Liu and J. C. K. Wang, International Journal of Science and Mathematics Education. 14, 1359-1376 (2015).

[22] B. Turnip, I. Wahyuni and Y. I. Tanjung, Journal of Education and Practice 7, 77-181 (2016).

[23] N. Sepriyanti, A. Fauzan, I. M. Arnawa and Lufri, International Journal Of Scientific \& Technology Research 6, 233-238 (2017).

[24] P. Imam, S. Imam and P. Ikrar, Journal of Physics. 1013, 012114 (2018).

[25] Saimun, Hanafi and Alkusaeri, International Journal Of Scientific \& Technology Research 8, 42-46 (2019).

[26] J. Brophy, J. Alleman and B. Knighton, A Learning Community in the Primary Classroom (Routledge, 270 Madison Avenue, New York, NY 10016, 2010), p. 245.

[27] A. M. Brower and K. M. Dettinger, About Campus: Enriching the Student Learning Experience. 3, 15-21 (1998).

[28] A. Davys, F. Howard, M. Rankine and A. Thompson, Practice: Social Work In Action. 0, 1-16 (2019).

[29] M. Munawar, English Education Journal (EEJ). 6, 484-496 (2015).

[30] T. Broadley, R. Martin, and E. Curtis, Frontiers in Education. 44, 1-15 (2019).

[31] P. D. Joseph A. Dimino and E. D. Mary Jo Taylor, Professional Learning Communities Facilitator's Guide for the What Works ClearinghouseTM Practice Guide Teaching Academic Content and Literacy to English Learners in Elementary and Middle School. (Regional Educational Laboratory Southwest (REL), Washington, DC: U.S, 2015), p. 3-8.

[32] B. S. Narmaditya, Winarning and D. Wulandari, Classroom Action Research Journal. 1, 1-11 (2017).

[33] M. Ali, Corrienna-Abd-Talib, N. H. Ibrahim, J. Surif and A. H. Abdullah, European Journal of Education Studies. 1, 1-10 (2016).

[34] E. Suprapti, H. Mursyidah and S. Inganah, International Journal of Trends in Mathematics Education Research. 1, 39-42 (2018).

[35] Miles M B and Huberman A M, An Expanded Sourcebook Qualitative Data Analysis Second Edition, (Sage Production Editor: Rebecca Holland, United States of America, 1994). 